\title{
Convergence to Common Fixed Points of Two Asymptotically Nonexpansive Type Mappings
}

\author{
SAFEER Hussain KHAN
}

\begin{abstract}
Common fixed points of two asymptotically nonexpansive type mappings have been approximated by strong convergence of an iteration scheme in a uniformly convex Banach space.
\end{abstract}

\section{INTRODUCTION}

Let $E$ be a real Banach space and $C$ a nonempty subset of $E$. Let $S$ : $C \rightarrow C$ be a mapping. $S$ is called asymptotically nonexpansive if for a sequence $\left\{k_{n}\right\} \subset[1, \infty)$ with $\lim _{n \rightarrow \infty} k_{n}=1,\left\|S^{n} x-S^{n} y\right\| \leq k_{n}\|x-y\|$ holds for all $x, y \in C$ and all $n=1,2, \ldots S$ is called a mapping of asymptotically nonexpansive type if $\limsup _{n \rightarrow \infty} \sup _{x \in C}\left\{\left\|S^{n} x-S^{n} y\right\|^{2}-\|x-y\|^{2}\right\} \leq 0$ holds for each $y \in C$. $S$ is also called uniformly $k$-Lipschitzian if for some $k>0,\left\|S^{n} x-S^{n} y\right\| \leq k\|x-y\|$ for all $n=1,2, \ldots$ and all $x, y \in C$. Asymptotically nonexpansive mappings have been studied by various authors. For example, see [2], [3], [4] and [5]. It follows from the definitions that every asymptotically nonexpansive mapping is an asymptotically nonexpansive type mapping but not conversely.

Khan and Takahashi [4] took the problem of approximating the common fixed points of two asymptotically nonexpansive mappings $S$ and $T$ through weak and strong convergence. Two mappings case has a direct link with the minimization problem, see for example [6]. Xu [8] proved the existence of a fixed point of asymptotically nonexpansive type mappings. Chang et al [1] studied the asymptotically nonexpansive type mappings $T$ (one mapping case) for convergence to fixed point through Ishikawa and Mann type iteration schemes. Keeping in view the importance of the common fixed points, we approximate, in this paper, the common fixed points of two asymptotically nonexpansive type mappings $S$ and $T$ through a more general scheme:

$$
x_{1} \in C, x_{n+1}=\left(1-\alpha_{n}\right) x_{n}+\alpha_{n} T^{n}\left[\left(1-\beta_{n}\right) x_{n}+\beta_{n} S^{n} x_{n}\right],
$$

2000 Mathematics Subject Classification. 47H05, 49M05.

Key words and phrases. Asypmtotically nonexpansive type mappings, strong convergence, iteration scheme, common fixed points. 
for all $n=1,2, \ldots$, where $\left\{\alpha_{n}\right\}$ and $\left\{\beta_{n}\right\}$ in $[0,1]$ satisfy certain conditions. Our results will generalize the corresponding results of [4] and [1].

\section{Preliminaries}

Let $E$ be a Banach space and let $C$ be a nonempty closed bounded convex subset of $E$. We need the following lemma which was first proved by Khan and Takahashi [4] for two mappings case.

Lemma 1. Let $E$ be a normed space and let $C$ be a nonempty bounded, closed and convex subset of E. Let, for $k>0, S$ and $T$ be uniformly $k$ Lipschitzian mappings of $C$ into itself. Define a sequence $\left\{x_{n}\right\}$ as

$$
x_{1} \in C, x_{n+1}=\left(1-\alpha_{n}\right) x_{n}+\alpha_{n} T^{n}\left[\left(1-\beta_{n}\right) x_{n}+\beta_{n} S^{n} x_{n}\right],
$$

for all $n=1,2, \ldots$, where $\left\{\alpha_{n}\right\}$ and $\left\{\beta_{n}\right\}$ are in $[0,1]$. If

$$
\lim _{n \rightarrow \infty}\left\|x_{n}-T^{n} x_{n}\right\|=0=\lim _{n \rightarrow \infty}\left\|x_{n}-S^{n} x_{n}\right\|,
$$

then

$$
\lim _{n \rightarrow \infty}\left\|x_{n}-T x_{n}\right\|=0=\lim _{n \rightarrow \infty}\left\|x_{n}-S x_{n}\right\| .
$$

The following characterization of a uniformly convex Banach space proved by $\mathrm{Xu}[7]$ will be used as well.

Lemma 2. Let $p>1$ and $r>0$ be two fixed real numbers. Then a Banach space $E$ is uniformly convex if and only if there is a continuous strictly increasing convex function $g:[0, \infty) \rightarrow[0, \infty)$ with $g(0)=0$ such that

$$
\|\lambda x+(1-\lambda) y\|^{p} \leq \lambda\|x\|^{p}+(1-\lambda)\|y\|^{p}-\omega_{p}(\lambda) g(\|x-y\|)
$$

for all $x, y \in U$ and $0 \leq \lambda \leq 1$ where $U$ is a unit ball of radius $r$ centred at 0 and

$$
\omega_{p}(\lambda)=\lambda^{p}(1-\lambda)+\lambda(1-\lambda)^{p} .
$$

In particular, for $p=2,(2.1)$ becomes

$$
\|\lambda x+(1-\lambda) y\|^{2} \leq \lambda\|x\|^{2}+(1-\lambda)\|y\|^{2}-\lambda(1-\lambda) g(\|x-y\|)
$$

We would also like to recall the definition of the semicompactness. A mapping $S$ is called semicompact if for any bounded sequence $\left\{x_{n}\right\}$ in $C$ with $\lim _{n \rightarrow \infty}\left\|x_{n}-S x_{n}\right\|=0$ there exists a subsequence $\left\{x_{n_{j}}\right\}$ of $\left\{x_{n_{i}}\right\}$ such that $x_{n_{j}} \rightarrow p \in C$ as $n_{j} \rightarrow \infty$.

Before we proceed further, we note that from definition of asymptotically nonexpansive type mapping it follows that for a fixed point $q \in F(S)$,

$$
\lim _{n \rightarrow \infty} \sup _{m \geq n} \sup _{x \in C}\left(\left\|S^{m} x-q\right\|^{2}-\|x-q\|^{2}\right) \leq 0 .
$$

Hence for given for given $\epsilon>0$, there exists a positive integer $n_{0}$ such that

$$
\sup _{m \geq n_{0}} \sup _{x \in C}\left(\left\|S^{m} x-q\right\|^{2}-\|x-q\|^{2}\right)<\epsilon .
$$




\section{Main Results}

First we prove our strong convergence theorem as follows.

Theorem 1. Let $E$ be a uniformly convex Banach space and let $C$ be its closed and convex subset. Let $S$ and $T$ from $C$ into itself be two uniformly $k$-Lipschitzian semicompact mappings of asymptotically nonexpansive type such that $\left\|S^{n} x-T^{n} y\right\| \leq\|x-y\|+\varepsilon_{n}$ for all $x, y \in C$ where $\varepsilon_{n} \rightarrow 0$ as $n \rightarrow \infty$. Define a sequence $\left\{x_{n}\right\}$ in $C$ as:

$$
x_{1} \in C, x_{n+1}=\left(1-\alpha_{n}\right) x_{n}+\alpha_{n} T^{n}\left[\left(1-\beta_{n}\right) x_{n}+\beta_{n} S^{n} x_{n}\right] \text {, }
$$

for all $n=1,2, \ldots$, where $\left\{\alpha_{n}\right\}$ and $\left\{\beta_{n}\right\}$ are sequences in $[0,1]$ such that $0<\delta \leq \alpha_{n}, \beta_{n} \leq 1-\delta<1$ for all $n=1,2, \ldots$. If $F(T) \cap F(S) \neq \phi$ then $\left\{x_{n}\right\}$ converges strongly to a common fixed point of $S$ and $T$.

Proof. Let $q$ be a common fixed point of $S$ and $T$. Put, for the sake of simplicity, $z_{n}=\left(1-\beta_{n}\right) x_{n}+\beta_{n} S^{n} x_{n}$. Then (3.1) can be written as $x_{n+1}=$ $\left(1-\alpha_{n}\right) x_{n}+\alpha_{n} T^{n} z_{n}$. Then using (2.2), we have

$$
\begin{aligned}
\left\|x_{n+1}-q\right\|^{2} & =\left\|\left(1-\alpha_{n}\right)\left(x_{n}-q\right)+\alpha_{n}\left(T^{n} z_{n}-q\right)\right\|^{2} \\
\leq & \left(1-\alpha_{n}\right)\left\|x_{n}-q\right\|^{2}+\alpha_{n}\left\|T^{n} z_{n}-q\right\|^{2}- \\
& -\alpha_{n}\left(1-\alpha_{n}\right) g\left(\left\|x_{n}-T^{n} z_{n}\right\|\right) .
\end{aligned}
$$

Since $E$ is a uniformly convex Banach space so by Lemma 2 there is an increasing function $g$ with $g(0)=0$. Therefore $g\left(\left\|x_{n}-T^{n} z_{n}\right\|\right) \geq 0$ and hence

$$
\begin{aligned}
\left\|x_{n+1}-q\right\|^{2} \leq & \left(1-\alpha_{n}\right)\left\|x_{n}-q\right\|^{2}+\alpha_{n}\left\|T^{n} z_{n}-q\right\|^{2} \\
\leq & \left\|x_{n}-q\right\|^{2}+\alpha_{n}\left(\left\|T^{n} z_{n}-q\right\|^{2}-\left\|z_{n}-q\right\|^{2}\right) \\
& +\alpha_{n}\left(\left\|z_{n}-q\right\|^{2}-\left\|x_{n}-q\right\|^{2}\right) \\
\leq & \left\|x_{n}-q\right\|^{2}+\alpha_{n}\left(\left\|T^{n} z_{n}-q\right\|^{2}-\left\|z_{n}-q\right\|^{2}\right) \\
& +\alpha_{n}\left[\beta_{n}\left(\left\|S^{n} x_{n}-q\right\|^{2}-\left\|x_{n}-q\right\|^{2}\right)-\right. \\
& \left.-\beta_{n}\left(1-\beta_{n}\right) g\left(\left\|x_{n}-S^{n} x_{n}\right\|\right)\right] \\
\leq & \left\|x_{n}-q\right\|^{2}-\frac{\delta^{3}}{2} g\left(\left\|x_{n}-S^{n} x_{n}\right\|\right) \\
& +\alpha_{n}\left(\left\|T^{n} z_{n}-q\right\|^{2}-\left\|z_{n}-q\right\|^{2}-\frac{\delta^{2}}{4} g\left(\left\|x_{n}-S^{n} x_{n}\right\|\right)\right) \\
& +\alpha_{n} \beta_{n}\left(\left\|S^{n} x_{n}-q\right\|^{2}-\left\|x_{n}-q\right\|^{2}-\frac{\delta}{4} g\left(\left\|x_{n}-S^{n} x_{n}\right\|\right)\right)
\end{aligned}
$$


Let $\eta=\inf _{n \geq 0}\left\|x_{n}-S^{n} x_{n}\right\|$. We now prove that $\eta=0$. Suppose on contrary that $\eta>0$. Since $g$ is continuous and increasing so

$$
g\left(\left\|x_{n}-S^{n} x_{n}\right\|\right) \geq g(\eta)>g(0)=0
$$

yields

$$
\begin{aligned}
\left\|x_{n+1}-q\right\|^{2} \leq & \left\|x_{n}-q\right\|^{2}-\frac{\delta^{3}}{2} g(\eta) \\
& +\alpha_{n}\left(\left\|T^{n} z_{n}-q\right\|^{2}-\left\|z_{n}-q\right\|^{2}-\frac{\delta^{2}}{4} g(\eta)\right) \\
& +\alpha_{n} \beta_{n}\left(\left\|S^{n} x_{n}-q\right\|^{2}-\left\|x_{n}-q\right\|^{2}-\frac{\delta}{4} g(\eta)\right)
\end{aligned}
$$

Since $S$ and $T$ are mappings of asymptotically nonexpansive type so, by (2.3), for a given $\frac{\delta^{2}}{4} g(\eta)$, there exists a positve integer $n_{0}$ such that

$$
\left\|S^{n} x_{n}-q\right\|^{2}-\left\|x_{n}-q\right\|^{2}<\frac{\delta^{2}}{4} g(\eta)<\frac{\delta}{4} g(\eta) \text { for all } n \geq n_{0}
$$

and

This gives

$$
\left\|T^{n} z_{n}-q\right\|^{2}-\left\|z_{n}-q\right\|^{2}<\frac{\delta^{2}}{4} g(\eta) \text { for all } n \geq n_{0} .
$$

$$
\left\|x_{n+1}-q\right\|^{2} \leq\left\|x_{n}-q\right\|^{2}-\frac{\delta^{3}}{2} g(\eta) \text { for all } n \geq n_{0} .
$$

so that

$$
\begin{aligned}
\sum_{n=n_{0}}^{m} \frac{\delta^{3}}{2} g(\eta) & \leq\left\|x_{n_{0}}-q\right\|^{2}-\left\|x_{m+1}-q\right\|^{2} \\
& \leq\left\|x_{n_{0}}-q\right\|^{2} \text { for all } m \geq n .
\end{aligned}
$$

Letting $m \rightarrow \infty$, we reach at a contradiction. Hence $\eta=0$. By definition of $\eta$ there is a subsequence $\left\{x_{n_{i}}\right\}$ of $\left\{x_{n}\right\}$ such that

$$
\left\|x_{n_{i}}-S^{n_{i}} x_{n_{i}}\right\| \rightarrow 0 \text { as } n_{i} \rightarrow \infty
$$

By Lemma 1,

$$
\left\|x_{n_{i}}-S x_{n_{i}}\right\| \rightarrow 0 \text { as } n_{i} \rightarrow \infty
$$

Since $S$ is semicompact there exists a subsequence $\left\{x_{n_{j}}\right\}$ of $\left\{x_{n_{i}}\right\}$ such that

$$
x_{n_{j}} \rightarrow p \in C \text { as } n_{j} \rightarrow \infty .
$$

Since $S$ is continuous so

$$
S x_{n_{j}} \rightarrow S p \text { as } n_{j} \rightarrow \infty
$$

Therefore by (3.5), $\|p-S p\|=0$ implies $p \in F(S)$ in $C$. Now $\left\|S^{n_{j}} x_{n_{j}}-p\right\| \leq$ $\left\|S^{n_{j}} x_{n_{j}}-x_{n_{j}}\right\|+\left\|x_{n_{j}}-p\right\|$ gives by virtue of (3.4) and (3.6) that

$$
\left\|S^{n_{j}} x_{n_{j}}-p\right\| \rightarrow 0 \text { as } n_{j} \rightarrow \infty .
$$


Now $z_{n_{j}}=x_{n_{j}}+\beta_{n_{j}}\left(S^{n_{i}} x_{n_{j}}-x_{n_{j}}\right)$. Therefore by (3.4) and (3.6),

$$
z_{n_{j}} \rightarrow p \text { as } n_{j} \rightarrow \infty
$$

Next, consider

$$
\begin{aligned}
\left\|T^{n_{j}} z_{n_{j}}-p\right\| & \leq\left\|T^{n_{j}} z_{n_{j}}-S^{n_{j}} x_{n_{j}}\right\|+\left\|S^{n_{j}} x_{n_{j}}-p\right\| \\
& \leq\left\|z_{n_{j}}-x_{n_{j}}\right\|+\epsilon_{n_{j}}+\left\|S^{n_{j}} x_{n_{j}}-p\right\| \\
& \leq\left\|z_{n_{j}}-p\right\|+\left\|x_{n_{j}}-p\right\|+\epsilon_{n_{j}}+\left\|S^{n_{j}} x_{n_{j}}-p\right\| \\
& \rightarrow 0 \text { as } n_{j} \rightarrow \infty .
\end{aligned}
$$

That is

$$
T^{n_{j}} z_{n_{j}} \rightarrow p \text { as } n_{j} \rightarrow \infty
$$

Moreover,

$$
\left\|z_{n_{j}}-T^{n_{j}} z_{n_{j}}\right\| \leq\left\|z_{n_{j}}-p\right\|+\left\|T^{n_{j}} z_{n_{j}}-p\right\| \rightarrow 0 \text { as } n_{j} \rightarrow \infty .
$$

So by Lemma $1,\left\|z_{n_{j}}-T z_{n_{j}}\right\| \rightarrow 0$ as $n_{j} \rightarrow \infty$. By continuity of $T, z_{n_{j}} \rightarrow p$ implies $T z_{n_{j}} \rightarrow T p$ and hence $p=T p$. Consequently $p \in F(T) \cap F(S)$. Now consider (3.2) again with $q=p$,

$$
\begin{aligned}
\left\|x_{n_{j}+1}-p\right\|^{2} & \leq\left\|x_{n_{j}}-p\right\|^{2}-\frac{\delta^{3}}{2} g\left(\left\|x_{n_{j}}-S^{n_{j}} x_{n_{j}}\right\|\right) \\
& +\alpha_{n_{j}}\left(\left\|T^{n_{j}} z_{n_{j}}-p\right\|^{2}-\left\|z_{n_{j}}-p\right\|^{2}-\frac{\delta^{2}}{4} g\left(\left\|x_{n_{j}}-S^{n_{j}} x_{n_{j}}\right\|\right)\right) \\
& +\alpha_{n_{j}} \beta_{n_{j}}\left(\left\|S^{n_{j}} x_{n_{j}}-p\right\|^{2}-\left\|x_{n_{j}}-p\right\|^{2}-\frac{\delta}{4} g\left(\left\|x_{n_{j}}-S^{n_{j}} x_{n_{j}}\right\|\right)\right)
\end{aligned}
$$

Then by (3.4), (3.6), (3.8), (3.9), (3.10), the fact that $g$ is continuous and $g(0)=0$ we obtain

$$
x_{n_{j}+1} \rightarrow p \text { as } n_{j} \rightarrow \infty
$$

Also

$$
\begin{aligned}
& \limsup _{n_{j} \rightarrow \infty}\left(\left\|S^{n_{j}+1} x_{n_{j}+1}-p\right\|^{2}-\left\|x_{n_{j}+1}-p\right\|^{2}\right) \\
\leq & \limsup _{n_{j} \rightarrow \infty} \sup _{x \in C}\left(\left\|S^{n_{j}+1} x-p\right\|^{2}-\|x-p\|^{2}\right) \\
\leq & \limsup _{n \rightarrow \infty} \sup _{x \in C}\left(\left\|S^{n} x-S^{n} p\right\|^{2}-\|x-p\|^{2}\right) \\
\leq & 0
\end{aligned}
$$

because $S$ is asymptotically nonexpansive type mapping. Since $x_{n_{j}+1} \rightarrow p$, therefore $\lim \sup _{n_{j} \rightarrow \infty}\left(\left\|S^{n_{j}+1} x_{n_{j}+1}-p\right\|^{2}\right) \leq 0$ and so

$$
\limsup _{n_{j} \rightarrow \infty}\left\|S^{n_{j}+1} x_{n_{j}+1}-p\right\|=0 \text { as } n_{j} \rightarrow \infty \text {. }
$$


Now $z_{n_{j}+1}=x_{n_{j+1}}+\beta_{n_{j+1}}\left(S^{n_{j+1}} x_{n_{j+1}}-x_{n_{j}+1}\right)$ gives by (3.11) and (3.12)

$$
z_{n_{j}+1} \rightarrow p \text { as } n_{j} \rightarrow \infty \text {. }
$$

Again

$$
\begin{aligned}
\left\|T^{n_{j}+1} z_{n_{j}+1}-p\right\| & \leq\left\|T^{n_{j}+1} z_{n_{j}+1}-S^{n_{j}} x_{n_{j}+1}\right\|+\left\|S^{n_{j}} x_{n_{j}+1}-p\right\| \\
& \leq\left\|z_{n_{j}+1}-x_{n_{j}+1}\right\|+\varepsilon_{n_{j}+1}+\left\|S^{n_{j}} x_{n_{j}+1}-p\right\| \\
& \leq\left\|z_{n_{j}+1}-p\right\|+\left\|x_{n_{j}+1}-p\right\|+\varepsilon_{n_{j}+1}+\left\|S^{n_{j}} x_{n_{j}+1}-p\right\| \\
& \rightarrow 0 \text { as } n_{j} \rightarrow \infty .
\end{aligned}
$$

That is $T^{n_{j}+1} z_{n_{j}+1} \rightarrow p$ as $n_{j} \rightarrow \infty$. Contining in this way, we can prove by induction that for any $m=0,1,2, \ldots, x_{n_{j}+m} \rightarrow p$ as $n_{j} \rightarrow \infty$. As a result $x_{n} \rightarrow p \in F(T) \cap F(S)$. This completes the proof.

Remark 1. Since every asymptotically nonexpansive mapping is of asymptotically nonexpansive type, Theorem 2 of [4] is now contained in the above theorem.

Remark 2. Theorems 2.1, 2.2, 2.3 and 2.4 of Chang et al [1], and the results generalized there, are all a special case of our above theorem.

\section{REFERENCES}

[1] S.S. Chang, Y.J. Cho, J.K. Kim, and K.H. Kim, Iterative approximation of fixed points for asymptotically nonexpansive type mappings in Banach spaces, PanAmer. Math. Journal 11(3)(2001), 53-63.

[2] K. Goebel and W.A. Kirk, A fixed point theorem for asymptotically nonexpansive mappings, Proc. Amer. Math. Soc., 35(1)(1972), 171-174.

[3] S.H. Khan and W. Takahashi, Iterative approximation of fixed points of asymptotically nonexpansive mappings with compact domains, PanAmer. Math. Journal 11(1)(2001), 19-24.

[4] S.H. Khan and W. Takahashi, Approximating common fixed points of two asymptotically nonexpansive mappings, Sci. Math. Jpn., 53(1)(2001), 143-148, e4, 133-138.

[5] J. Schu, Iterative construction of fixed points of asymptotically nonexpansive mappings, J. Math. Anal. Appl. 158(1991), 407-413.

[6] W. Takahashi, Iterative methods for approximation of fixed points and thier applications, J.Oper.Res.Soc. Jpn., 43(1)(2000), 87-108.

[7] H.K. Xu, Inequalities in Banach spaces with applications, Nonlinear Anal. TMA, 16(12)(1991), 1127-1138.

[8] H.K. Xu, Existence and convergence for fixed points of mappings of asymptotically nonexpansive type, Nonlinear Anal. TMA,16(12)(1991), 1139-1146.

Current address:

\section{SAFEer Hussain KHAN}

Department of Mathematics, Statistics and Physics

QATAR UNIVERSITY

DOHA 2713

STATE OF QATAR

E-mail address: safeerhussain5@yahoo.com 